\title{
Effect of atomic number and atomic weight on time-dependent inelastic deformation in metals
}

\author{
V. Monfared ${ }^{1 *}$, S. Daneshmand ${ }^{2}$, A. H. Monfared ${ }^{3}$ \\ ${ }^{1}$ Department of Mechanical Engineering, Zanjan Branch, Islamic Azad University, Zanjan, Iran \\ ${ }^{2}$ Department of Mechanical Engineering, Majlesi Branch, Islamic Azad University, Isfahan, Iran \\ ${ }^{3}$ Department of Industrial Intelligence Research Group. ACECR, Zanjan Branch, Iran
}

Received 18 December 2013, received in revised form 19 July 2014, accepted 19 July 2014

\begin{abstract}
Principal purpose of this research is to study the effect of atomic number and atomic weight on behavior of time-dependent inelastic deformation in metals. For achieving this purpose, analytical and semi-analytical methods are used for analyzing the behavior of the deformations. The elements such as silver, aluminum and nickel are selected for validation of the presented method and obtained results. The effect of other important parameters is investigated for predicting time-dependent behavior of creeping metals. As a result, we can control creep behavior in metals in order to prevent creep rupture. Finally, good agreement is found between presented method and available experimental results.
\end{abstract}

K e y w or d s: creep, metals \& alloys

\section{Introduction}

Dependence of inelastic deformation rates, such as creep strain rate, on the atomic properties is one of the interesting and important problems in the material science, mechanics and physics. The relation of some important parameters, such as creep strain rate $\left(\dot{\varepsilon}_{\text {creep }}\right)$, with natural and organic properties such as atomic number $(Z)$ has not been determined yet. This relation between plastic time-dependent deformation and atomic number is very prominent for plasticity problems. This research attempts to find the relation for predicting creep strain rate behavior. Different insight is introduced by developing relations between the atomic properties and the mechanical behavior.

The creep deformation is an important phenomenon in physics and mechanics, in which materials deform under elevated temperatures and loads change continuously over the time. In this article, the effect of ten factors on the creep behavior in metals is investigated.

Many researchers studied some related subjects such as creep, relaxation and plastic deformation [110]. For example, pulling out and extraction of a stainless steel wire inserted into an epoxy resin have been analyzed as a function of the embedded length using shear lag model [1]. In addition, creep exponential Dorn law was used for predicting creep behavior of the composites [4]. Also, the aim of the work presented in reference [7] is to find how the creep applied at different temperatures influences the reversible structural relaxation of the Ni-rich amorphous alloy. Zhang et al. [8] analyzed experimentally viscous creep occurring in perpendicularly aligned carbon nanotubes (VA-CNTs). Nanoindentation experiments were performed to illustrate the creep behavior of nanotube materials. Newly, steady state creep behavior of the fibrous composites has been studied using the mapping, logarithmic functions (MF) and dimensionless parameter (DP) techniques with considering creep exponential law (Dorn law) [9].

Moreover, a novel analytical method has been presented to investigate the steady state creep in the short fiber polymer matrix composites using complex variable method, in which both the fiber and matrix creep under low stresses and temperatures in a state of plane stress [10]. Positron annihilation in steel samples deformed by uniaxial tension and structural changes in deformed soft magnetic Ni-based metallic glass studies have been performed $[11,12]$. For instance, ACAR

*Corresponding author: tel./fax: +98-24-33460063;

e-mail addresses: vahid_monfared@alum.sharif.edu , v.monfared@yahoo.com 
method was applied to investigate changes in annihilation parameters during deformation (by uniaxial tension) of the ST2 SAL steel samples [11]. Furthermore, the relations between atomic number and composition weight ratio in smart material have been investigated [13]. Important studies on effective atomic numbers have been extensively performed in some materials by many researchers [14-21]. Novel, trustworthy and practical semi-empirical equation based on the total interaction cross sections $\left(\sigma_{\mathrm{t}}\right)$ was proposed to obtain the values of the effective atomic number $\left(Z_{\text {eff }}\right)$ of the $3 \mathrm{~d}$ transition metal alloys [21].

For calculation of the results, references [22-24] have been used for extracting required values such as elastic modulus, atomic number, etc. In addition, different kinds of research on plastic-elastic deformation have been carried out [25-28]. For example, second stage creep behavior of pure aluminum has been analyzed using constant structure creep experiments performed in the $2^{\text {nd }}$ stage creep over a wide temperature interval from 523 to $773 \mathrm{~K}$ [25]. An experiment with a new device to determine torsion deformation as a function of applied torque has been done and analyzed, which permitted construction of the hysteresis cycle for a rubber hose and various tubes [28]. Recently, some important behavior types such as radial, circumferential, axial, shear and equivalent stress behavior have been predicted using an approximation of creep constitutive equations ACCE and Dorn law [29]. In addition, inelastic time dependent behavior of the short fiber composites has been studied using special functions and an exponential creep Dorn law [30]. Novel models such as quasi shear-lag and semi-analytical models have been presented for predicting the creep behavior of the short fiber composites [31].

As observed, it is necessary to present a new method for predicting the creep strain rate behavior using atomic and mechanical properties without using complex approaches and difficult experimental methods. In this way, a simple approach is proposed for predicting the time-dependent behavior in metals using some parameters such as atomic number, atomic weight and elastic and shear modulus, etc. The atomic number, atomic weight, Poisson's ratio, elastic and shear modulus, ultimate tensile strength, density and melting point are the effective parameters for obtaining the small time-dependent deformations.

Presented method can be useful and applicable for designing purposes including mechanical design based on the creep criterion and behavior. Therefore, inelastic time-dependent behavior is predicted by weighted calculus, meta-calculus (computer codes) and available experimental results in the same metals. In other words, the proposed method is similar to the nonlinear regression and neural network approach. The results of the novel work are validated through comparison with available experimental results for the elements of silver, aluminum and nickel. So, the main objective of the presented research is to predict the creep strain rate behavior using atomic and mechanical properties.

\section{Materials and methods}

In this section, materials and methods are introduced for predicting the time-dependent behavior using related effective parameters of metals. In this way, the general form of the creep strain rate is given as follows [32]:

$$
\left.\dot{\varepsilon}\right|_{\text {general }}=f(\sigma, t, T),
$$

where $\sigma, t$ and $T$ are respectively applied stress, time and temperature. In this work, the above general formulation (Eq. (1)) is extended to the following forms:

$$
\begin{aligned}
\left.\dot{\varepsilon}\right|_{\text {particular }}= & f\left(Z, W, \sigma, t, T, E, G, v, S_{\mathrm{ut}}, \rho\right), \\
\left.\dot{\varepsilon}\right|_{\text {particular }} & =f_{1}(Z) f_{2}(W) f_{3}(\sigma) f_{4}(t) f_{5}(T) . \\
& \cdot f_{6}(E) f_{7}(G) f_{8}(v) f_{9}\left(S_{\mathrm{ut}}\right) f_{10}(\rho),
\end{aligned}
$$

where $Z, W, \sigma, t, T, E, G, v, S_{\mathrm{ut}}$, and $\rho$ are respectively atomic number, atomic weight, applied stress $(\mathrm{MPa})$, time $(\mathrm{s})$, temperature (including melting $\left(T_{\mathrm{m}}\right)$ and exerted $\left(T_{\mathrm{e}}\right)$ temperatures $(\mathrm{K})$ ), elastic modulus (GPa), shear modulus (GPa), Poisson's ratio, ultimate tensile strength $(\mathrm{GPa})$, and density $\left(\mathrm{g} \mathrm{ml}^{-1}\right)$.

In what follows, a weighted function is considered for each parameter using numerical methods, weighted calculus (computer coding: Matlab codes), meta-calculus and available results with considering nonlinear regression and neural network approaches.

General formulation for determining the creep strain rate is given below in the form using Dorn law:

$$
\left.\dot{\varepsilon}\right|_{\text {particular }}=D \exp \left(\left.\alpha \sigma\right|_{\text {particular }}\right) .
$$

Equation (4) is converted to the following form:

$$
\log \left(\left.\dot{\varepsilon}\right|_{\text {particular }}\right)=\Psi+\left.\chi \sigma\right|_{\text {particular }},
$$

where

$$
\begin{aligned}
& \Psi=a_{1} \ln \left(\frac{T_{\mathrm{m}}}{T_{\mathrm{e}}}\right)+a_{2} \frac{E Z v}{G}+a_{3} \frac{W S_{\mathrm{ut}}}{\rho}, \\
& \chi=b_{1} \ln \left(\frac{T_{\mathrm{m}}}{T_{\mathrm{e}}}\right)+b_{2} \frac{E Z v}{G}+b_{3} \frac{W S_{\mathrm{ut}}}{\rho} .
\end{aligned}
$$

In Eqs. (6) and (7), $a_{i}$ 's and $b_{i}$ 's are the particular weights. They are determined using analytical, semi-analytical and numerical approaches such as weighted 
calculus (computer coding and simulating) or meta-calculus along with nonlinear regression and neural network approaches. The mentioned time-dependent formulations are to predict the creep strain rate behavior in the steady state creep using atomic and mechanical properties.

$T_{\mathrm{m}}$ and $T_{\mathrm{e}}$ indicate the melting point and applied temperature, respectively. In this way, physical, chemical and engineering visions are beneficial and effective for obtaining these parameters by the mentioned methods correctly. Available experimental results are also used for validating the presented research results. The time-dependent small deformation behavior of silver $(\mathrm{Ag})$, aluminum $(\mathrm{Al})$ and nickel $(\mathrm{Ni})$ is considered for verifying the obtained results. After exact calculating, coefficients $a_{i}$ 's and $b_{i}$ 's are obtained by the mentioned methods. Here, the meaning of the weight functions are the weight coefficients (i.e., numbers of $-16.71,-0.0201,0.0421,-0.3803,0.0099,0.0488$ are the mentioned coefficients). It accordingly yields:

$$
\begin{gathered}
\Psi \cong-16.71 \ln \left(\frac{T_{\mathrm{m}}}{T_{\mathrm{e}}}\right)-0.0201 \frac{E Z v}{G}+0.0421 \frac{W S_{\mathrm{ut}}}{\rho}, \\
\chi \cong-0.3803 \ln \left(\frac{T_{\mathrm{m}}}{T_{\mathrm{e}}}\right)-0.0099 \frac{E Z v}{G}+0.0488 \frac{W S_{\mathrm{ut}}}{\rho} .
\end{gathered}
$$

For example, for silver $(\mathrm{Ag})$, some mentioned parameters presented in Eqs. (8) and (9), such as atomic number, atomic weight and density, respectively, are $Z=47, W=107.87$ and $\rho=10.5 \mathrm{~g} \mathrm{ml}^{-1}[22-24]$. Therefore, the presented method can be used for predicting the steady state creep behavior without performing difficult and complex experimental, numerical and analytical methods. As mentioned before, the unknown coefficients $a_{i}$ 's and $b_{i}$ 's are obtained using the analytical, semi-analytical and numerical approaches such as weighted calculus (computer coding and simulating), or meta-calculus with considering nonlinear regression and neural network approaches.

\section{Results and discussion}

In this section, the obtained results of the present work are compared with the available experimental results $[2-6]$. In this way, the elements such as silver $(\mathrm{Ag})$, aluminum $(\mathrm{Al})$ and nickel $(\mathrm{Ni})$ are chosen for comparing the obtained results. As mentioned before, the properties of the mentioned materials and elements are also available in various references [2224]. The creep tensile test specimen used in reference [3] for analyzing the steady state creep behavior is shown in Fig. 1.

Comparison of two methods (presented and experimental one) for obtaining the small time-dependent

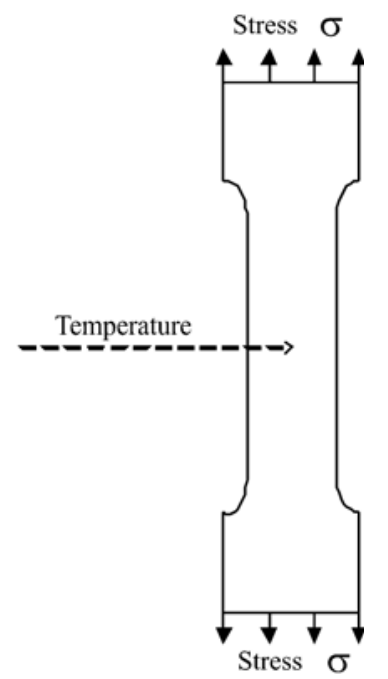

Fig. 1. Tensile test specimen for analyzing the steady state creep behavior.

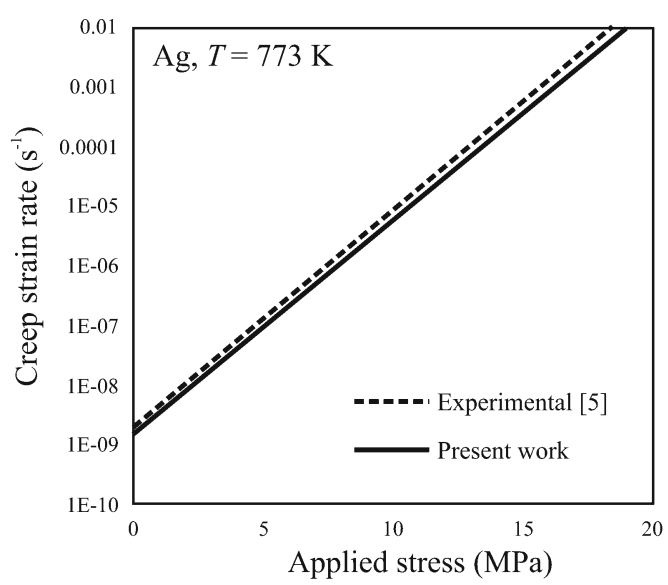

Fig. 2. Comparison between the present work and experimental results [5] for $\mathrm{Ag}$ at $773 \mathrm{~K}$.

deformation behavior (permanent or second stage creep) is shown in Figs. 2-4. In the presented figures (Figs. 2-4), interesting results are observed for better comparison of the obtained results, and suitable and proper compatibilities are also seen. The mentioned suitable compatibilities are arising from the correct and exact analytical and semi-analytical computations.

Then, the obtained results of the analytical and semi-analytical approaches and available experimental results $[3,5]$ are compared together for validating the presented method (see Fig. 2 for Ag).

Afterwards, the creep strain rate with respect to applied stress is obtained and predicted for $\mathrm{Ni}$ at $1073 \mathrm{~K}$ (see Fig. 3 for Ni).

The mentioned creep behavior of unreinforced metals was tested in the references $[3,5]$ experiment- 


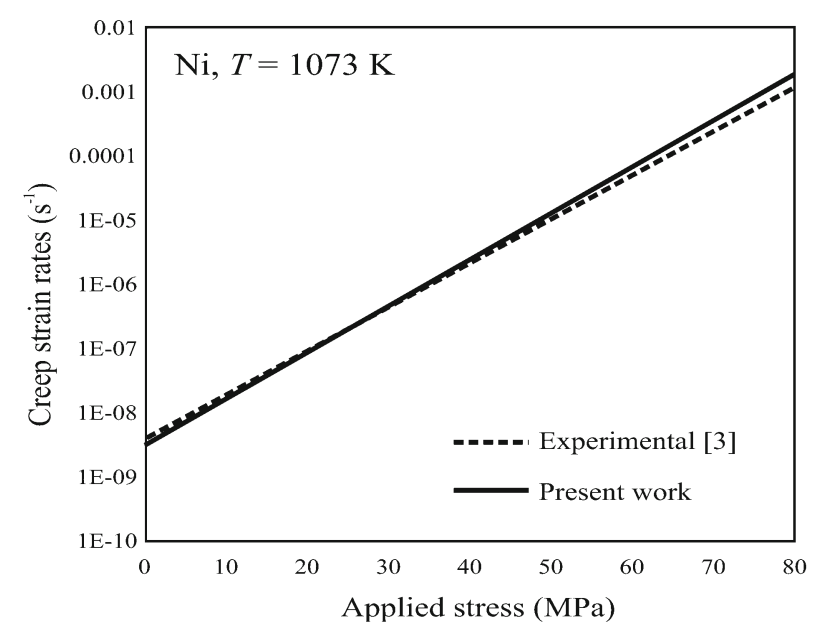

Fig. 3. Comparison between present work and experimental results [3] for $\mathrm{Ni}$ at $1073 \mathrm{~K}$.

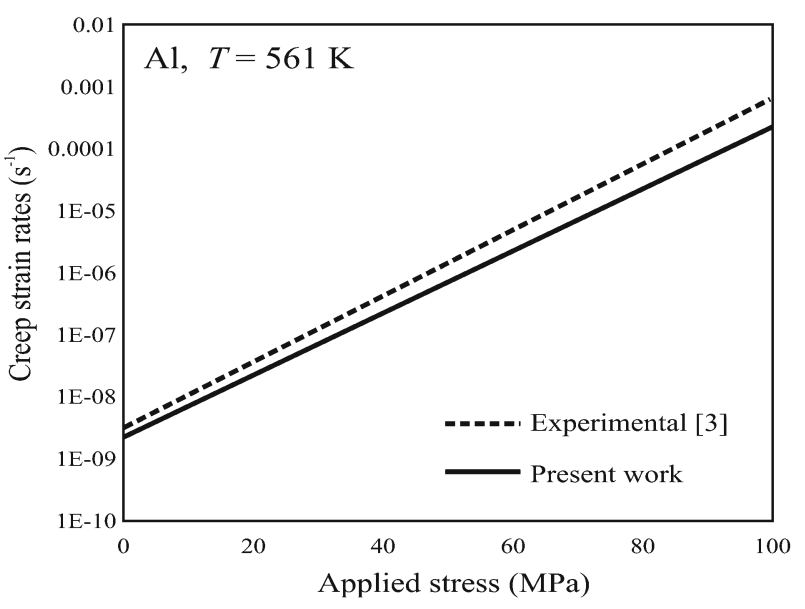

Fig. 4. Comparison between present work and experimental results [3] for $\mathrm{Al}$ at $561 \mathrm{~K}$.

ally at various temperatures and constant stresses using the specimen shown in Fig. 1. The overall creep strain rates remain very small in all creep tests (see Fig. 4 for $\mathrm{Al}$ ).

Figures 2-4 show good agreement between two methods (presented and experimental [3, 5] methods). As considered, gradients of all curves presented in Figs. 2-4 are very smooth, because these time dependent small deformations are in the steady state and permanent creep. Linear behavior of the creep deformations is arising from the stepped and smooth deformations over the time under constant stress and temperature.

Accordingly, the proposed method can be used for predicting the permanent and steady state creep behavior of metals using the mentioned parameters such as atomic number, atomic weight, elastic modulus, etc. with considering the mentioned coefficients.

As an application, the presented method can be employed for the creep analysis in composite materials, visco-elasto-plastic engineering problems and mechanical design subjected to high temperature and stress because of its high performance for predicting the creep behavior. Furthermore, the gradient and slope of $\left.\sigma\right|_{\text {applied }}-\left.\dot{\varepsilon}\right|_{\text {general }}$ curves and diagrams may help us to predict creep rupture domains in the second stage creep. In other words, we can control the slope and gradient of the obtained creep curves in order to prevent fast creep rupture. In these cases, high slopes and gradients for $\left.\sigma\right|_{\text {applied }}-\left.\dot{\varepsilon}\right|_{\text {general }}$ curves and diagrams are unfavorable for the designing purpose, because with the slope increasing, the creep strain rate extensively increases at low stresses, and this state is resulting in the fast creep rupture. So, presented formulation can help us to control the mentioned slopes and gradients in order to enhance the factor of safety.

\section{Conclusions}

In this research work, an effect of the atomic number, atomic weight and other related important parameters on inelastic time-dependent deformations was studied, and the steady state creep behavior of the metals was investigated. In this new insight, the analytical and semi-analytical methods such as weighted and meta-calculus were used. Nonlinear regression, neural network approaches and available results were employed for the creep analysis. According to the obtained results, it is concluded that all material properties and natural characteristics such as atomic number, atomic weight and elastic modulus affect the creep behavior in metals. Moreover, the analytical and semianalytical approaches were introduced for predicting the time-dependent behavior of the creeping materials using weighting functions, computer codes (simulations), nonlinear regression and neural network approaches. One of important applications of the presented method is in the control of the creep phenomenon and mechanical design based on the creep criterion. Finally, an unknown behavior can be determined by the atomic properties and characteristics.

\section{References}

[1] Takaku, A., Arridge, R. G. C.: J Phys D Appl Phys, 6, 1973, p. 2038. doi:10.1088/0022-3727/6/17/310

[2] Nieh, T. G.: Metall Trans A, 15, 1984, p. 139. doi:10.1007/BF02644396

[3] Lilholt, H.: Compos Sci Technol, 22, 1985, p. 277. doi:10.1016/0266-3538(85)90065-X

[4] Morimoto, T., Yamaoka, T., Lilholt, H., Taya, M.: J Eng Mater Technol, 110, 1988, p. 70. doi:10.1115/1.3226032 
[5] Dragon, T. L., Nix, W. D.: Acta Metal Mater, 38, 1990, p. 1941. doi:10.1016/0956-7151(90)90306-2

[6] Dragon, T. L., Nix, W. D.: Acta Metal Mater, 40, 1992, p. 2781. doi:10.1016/0956-7151(92)90348-I

[7] Juríková, A., Csach, K., Miškuf, J., Ocelík, V.: Acta Phys Pol A, 113, 2008, p. 99.

[8] Zhang, Q., Lu, Y. C., Du, F., Dai, L., Baur, J., Foster, D. C.: J Phys D: Appl Phys, 43, 2010, p. 1. doi:10.1051/epjap:2008143

[9] Monfared, V., Mondali, M., Abedian, A.: Arch Civ Mech Eng, 12, 2012, p. 455.

[10] Monfared, V., Mondali, M., Abedian, A.: Proc IMechE Part C: J Mech Eng Sci, 227, 2013, p. 2182. doi:10.1177/0954406212473391

[11] Rudzinska, W., Szuszkiewicz, M., Bujnarowski, G., Kluza, A. A.: Acta Phys Pol A, 113, 2008, p. 1507.

[12] Juríková, A., Csach, K., Miskuf, J., Ocelík, V.: Acta Phys Pol A, 115, 2009, p. 393.

[13] Monfared, V., Khalili, M. R.: Acta Phys Pol A, 120, 2011, p. 424.

[14] Hopkins, T. C., Bastow, B. D.: J Phys D: Appl Phys, 7, 1974, p. 199. doi:10.1088/0022-3727/7/1/328

[15] Murty, V. R. K., Winkoun, D. P., Devan, K. R. S.: Appl Radiat Isotopes, 53, 2000, p. 945. doi:10.1016/S0969-8043(00)00248-7

[16] Içelli, O., Erzeneoğlu, S., Karahan, I. H., Çankaya, G.: J Quant Spectrosc Ra, 91, 2005, p. 485. doi:10.1016/j.jqsrt.2004.07.006

[17] Han, I., Demir, L.: Nucl Instrum Meth B, 267, 2009, p. 3505. doi:10.1016/j.nimb.2009.08.022

[18] Han, I., Demir, L.: Radiat Meas, 44, 2009, p. 289. doi:10.1016/j.radmeas.2009.03.010
[19] Han, I., Demir, L.: Nucl Instrum Meth B, 267, 2009, p. 3. doi:10.1016/j.nimb.2008.10.004

[20] Medhat, M. E.: Ann Nucl Energy, 38, 2011, p. 1252. doi:10.1016/j.anucene.2011.02.007

[21] Han, H., Aygun, M., Demir, L., Sahin, Y.: Ann Nucl Energy, 39, 2012, p. 56. doi:10.1016/j.anucene.2011.09.008

[22] Wieser, M. E., Coplen, T. B.: Pure Appl Chem, 83, 2011, p. 359.

[23] Grote, K. H., Antonsson, E. K.: Handbook of Mechanical Engineering. New York, Springer 2009.

[24] Hertzberg, R. W., Vinci, R. P., Hertzberg, J. L.: Deformation and Fracture Mechanics of Engineering Materials. New York, Wiley 2012.

[25] Milička, K.: Kovove Mater., 49, 2011, p. 307.

[26] Kawasaki, M., Sklenička, V., Langdon, T. G.: Kovove Mater., 49, 2011, p. 75.

[27] Lapin, J., Pelachová, T., Gebura, M.: Kovove Mater., 50, 2012, p. 379.

[28] Romo-Kröger, C. M.: Eur J Phys, 33, 2012, p. 551. doi:10.1088/0143-0807/33/3/551

[29] Monfared, V., Mondali, M., Abedian, A.: J Mech Sci Technol, 27, 2013, p. 3277. doi:10.1007/s12206-013-0850-z

[30] Mondali, M., Monfared, V., A bedian, A.: CR Mecanique, 341, 2013, p. 592. doi:10.1016/j.crme.2013.04.004

[31] Monfared, V., Mondali, M.: Mater Design, 54, 2014, p. 368. doi:10.1016/j.matdes.2013.08.040

[32] Boyle, J. T., Spence, J.: Stress Analysis for Creep. Southampton, Butterworth 1983. 